

\section{Abstract}

Objectives: To examine the relationship between both individual and neighborhood level characteristics and non-fasting blood glucose levels.

Study design: This study used a cross sectional design using data from the Community Initiative to Eliminate Stroke Program in NC (2004-2008). A total of 12,809 adults nested within 550 census block groups from two adjacent urban counties were included in the analysis.

Methods:Participants completed a cardiovascular risk factor assessment with self-reported demographics, stroke-risk behaviors, and biometric measurements. Neighborhood level characteristics were based upon census data. Three multilevel models were constructed for data analysis.

Results: Mean blood glucose level of this sample population was $103.61 \mathrm{mg} / \mathrm{dL}$. The unconditional model 1 suggested a variation in mean blood glucose levels among the neighborhoods ( $T 00=13.39 ; \mathrm{P}<.001$ ). Both models 2 and 3 suggested that the neighborhood composite deprivation index had a significant prediction on each neighborhood's mean blood glucose level $\left(\mathrm{i}_{01}=.69 ; \mathrm{P}<0.001, \mathrm{i}_{01}=.36 ; \mathrm{P}=.004\right)$. Model 3 also suggested that across all the neighborhoods, on average, after controlling for individual level risk factors, deprivation remained a significant predictor of blood glucose levels.

Conclusions: The findings provide evidence that neighborhood disadvantage is a significant predictor of neighborhood and individual level blood glucose levels. One approach to diabetes prevention could be for policymakers to address the problems associated with environmental determinants of health

Keywords: multilevel; deprivation index; prevention; non-fasting blood glucose level; type 2 diabetes 


\title{
The Influence of Neighborhood Poverty on Blood Glucose Levels: Findings from the Community Initiative to Eliminate Stroke (CITIES) program
}

\author{
M.L Cathorall, H. Xin, R. Aronson, A. Peachey, D. L. Bibeau, M. Schulz, \& G. Dave
}

\section{Introduction}

Diabetes Mellitus is a serious health issue among American adults and complex public health problem that warrants development and implementation of innovative strategies to address its high morbidity and mortality (Centers for Disease Control and Prevention [CDC], 2011). In 2011, an estimated 26 million Americans (8.3\% of the population) had diagnosed or undiagnosed diabetes. Among people aged 20 years or older, the proportion with diabetes increased to $11.3 \%$. Among those aged 65 years and older, $26.9 \%$ were estimated to have diabetes. Racial/ethnic minorities, particularly African Americans, have disproportionately higher diabetes-related morbidity and mortality (CDC, 2011). They are almost twice as likely to be diagnosed with and die from diabetes, compared to whites (Schiller, Lucas, Ward, \& Peregoy, 2012). These disparities at the intersection of race and geography reflect the dynamic interplay between biology, individual risk factors, sociocultural environmental barriers and system-level factors. In addition, diabetes can lead to other debilitating and chronic conditions such as cardiovascular diseases, stroke, kidney diseases, and nervous system diseases. It was the seventh leading cause of death in 2010 (Hoyert \& $\mathrm{Xu}, 2012$ ). In 2007 approximately $\$ 174$ billion was spent on direct and indirect diabetes related healthcare (CDC, 2011) and these costs are predicted to increase by at least 50\% by 2034 (Huang, Basu, O'Grady, \& Capretta, 2009). Approximately $35 \%$ of U.S. adults aged 20 years or older had prediabetes identified by impaired fasting glucose (CDC, 2011). This poses a significant threat to and burden on the current healthcare systems that warrants attention and prioritization.

Non-insulin dependent type 2 diabetes mellitus (NIDDM) can be reduced through modifying or controlling an individual's current conditions and/or lifestyles. Modifiable risk factors that increase an individual's risk of developing type 2 diabetes include physical inactivity or leading a sedentary lifestyle, and weight gain or body fat redistribution (Ford, Williamson \& Liu, 1997; Koh-Banerjee, Wang, Hu, et al., 2004). A review of epidemiological studies indicated that physically active people had a 30-50\% lower chance of developing type 2 diabetes than sedentary individuals. The protective mechanisms of physical activity in reducing the incidence of diabetes included controlling body weight, reducing blood glucose levels, increasing insulin sensitivity, and reducing insulin resistance (Bassuk \& Manson, 2005). Overweight or obesity is one of several modifiable risk factors for type 2 diabetes (Carey, Walters, Colditz, et al., 1997). Compared to adults with a normal weight, adults with a BMI of 29.9 or higher were 1.59 to 7.37 times more likely to have diagnosed diabetes (Mokdad, Ford, Bowman, et al., 2003). Smoking is another modifiable risk factor for type 2 diabetes (Miller, Schulz, Bibeau, Galka, Spann, Martin, Aronson, \& Chase, 2007).

The Influence of Neighborhood Poverty on Blood Glucose Levels Volume 8, No. 2 (2015) | ISSN 2161-6590 (online) | DOI 10.5195/hcs.2015.184 | http://hcs.pitt.edu 
A consistent and significant dose-response relationship reported in multiple studies suggested that the incidence of type 2 diabetes among heavy smokers ( $>=20$ cigarettes per day) was greater than the incidence among lighter smokers (Willi, Bodenmann, Ghali, et al., 2007). Low education, poor socioeconomic status and non-modifiable risk factors including increasing age, differences in ethnicity, and family history of diabetes all can contribute to an increased risk of diabetes (Harris, 1991; Harris, Klein, Cowie, et al., 1998; Joshy, Porter, Levre, et al., 2009; Pan, Yang, Li, et al., 1997; Robbins, Vaccarino, Zhang, et al., 2001).

In addition to the modifiable and non-modifiable individual risk factors described above, neighborhood characteristics have been found to be associated with an increased incidence and prevalence of type 2 diabetes either through a direct impact on an individual adult's glycemia or an indirect influence on individuals' risk factors. A prospective study, following residents of two neighborhoods for a median of 5 years, found that residents in the neighborhood with more resources (e.g. facilities for exercise, accessibilities to healthy food) had a 38\% lower chance of developing type 2 diabetes compared to residents living in the neighborhood with fewer resources (Auchincloss, Diez-Roux, Mujahid, et al., 2009). Other studies suggested that the extent of neighborhood poverty has a significant association with type 2 diabetes rates (Krishnan, Cozier, Rosenberg et al., 2010; Menec, Shooshtari, Novicki, et al., 2010). Individuals living in neighborhoods with higher deprivation had the highest incidence of type 2 diabetes. This was also true among the more educated and higher income participants living in more-deprived neighborhoods (Auchincloss, Diez-Roux, Mujahid, et al., 2009). In addition, even when you have better neighborhood resources, if that neighborhood is surrounded by resource-deprived neighborhoods, then the incidence of type 2 diabetes will remain high (Cox, Boyle, Davey, et al., 2007).

Adverse neighborhood housing conditions were identified as associated with an increased type 2 diabetes incidence among middle aged African Americans (Schootman, Andersen, Wolinsky, et al., 2007). This effect was independent of other poor neighborhood conditions. Neighborhood built environment (e.g. concentration of fast food outlets or restaurants, walkability, safety, and socioeconomic status) has been shown to have a significant inverse association with overweight and obesity among different age and ethnic groups (Inagami, Cohen, Brown, et al., 2009; Lovasi, Hutson, Guerra, et al., 2009; Sallis, Saelens, Frank, et al., 2009). Walkability, accessibility to and availability of exercise facilities, and neighborhood socioeconomic status were significantly associated with the amount of physical activity individuals get, which was subsequently linked to the development of obesity and being overweight (Gordon-Larsen, Nelson, Page, et al., 2006; Taylor, Carlos, Poston, Jones, et al., 2006).

The purpose of this study is to explore: (CDC, 2011) the relationship between neighborhood level deprivation and individual blood glucose levels, (Carey, Walters, Colditz, et al., 1997) the amount of variance in blood glucose levels between neighborhoods that is explained by deprivation, and (Mokdad, Ford, Bowman, et al., 2003) the aggregate influence of individual risk factors and deprivation on individual blood glucose levels across all neighborhoods. Non-fasting blood glucose levels were used as an indicator of diabetes (Mayo Clinic, 2010; National Institutes of Health [NIH], 2008). This study examined data from the Community Initiative to Increase Risk Awareness and Eliminate Stroke (CITIES) program in NC.

\section{Methodology}

\section{Data}

The CITIES program was funded by the Office of Minority Health with a four-year grant period from August 1, 2004 to July 31, 2008 [29]. The goal of this program was to "complement and enhance existing local, regional and national activities designed to contribute to reducing and ultimately eliminating the excessive rates of stroke in the southeastern region of the U.S." (2005). The Moses H. Cone Health System, Novant Health Systems, and University of North Carolina at Greensboro (UNCG) partnered with the Forsyth Medical Foundation to carry out project activities in Forsyth and Guilford counties. This project was approved by the Institutional Review Boards of Novant Health Systems and UNCG. 


\section{Sample}

A convenience sample of 19,261 adult participants residing in Forsyth and Guilford County were recruited. Mobile units were located throughout Forsyth and Guilford counties where individuals could voluntarily complete a community screening for early detection of stroke risk factors. Using U.S. census data 2000 and ArcGIS 9.3 (Environmental Systems Research Institute, Redlands, CA), 15,171 participants with a complete in-state address were successfully geocoded. Of the participant addresses that were geocoded, a total of 12,904 participants with a record of non-fasting blood glucose remained. After eliminating outliers with extreme blood glucose values and 26 census blocks having less than 5 participants, the final sample included 12,809 participants or cases nested within 550 census block groups. For this study a census block group was defined as a proxy for a neighborhood (Auchincloss, Diez,Roux, Mujahid, et al., 2009; Krishnan, Cozier, Rosenberg, et al., 2010; Inagami, Cohen, Brown, et al., 2009).

\section{Measures \& Instrument}

The HealthWise Cardiovascular Risk Factor Assessment/Recommendations was a paper-screening tool used to record interviews and clinical data related to participants' stroke risk factors in this study. It was developed by the Moses Cone Stroke Center and Heart and Vascular Center. It consisted of participants' demographic and physical characteristics, self-reported cardiovascular risk factors, laboratory results, and specific recommendations from the nurses. The screening form was completed by registered nurses from the two hospital systems. The details about the instrument are described elsewhere (Miller, Schulz, Bibeau, Galka, Spann, Martin, Aronson, \& Chase, 2007).

Dependent variable. Non-fasting blood glucose level was a continuous individual dependent variable in this study. Each participant had a plasma glucose test at the time of the screening. A registered nurse took a finger blood sample, and the blood glucose level was measured using a calibrated Cholestech LDX machine in mg/dL.

Individual independent variables. In total, seven individual independent variables were included for analysis. Five of them were categorical variables: (1) Gender: male or female, (2) Race: White, African-American, or other, (3) Education: less than high school, high school graduate/General Educational Development (GED), or more than high school, (4) Self-reported smoking: no or yes, and (5) Self-reported do you lack physical activity in your life: no or yes. Two variables were continuous: Age; and BMI: calculated by using self-reported height in inches and measured weight in pounds.

Neighborhood independent variable. Census block groups served as neighborhood identifiers. One census block group contains between 600 and 3,000 residents (US Census Bureau, n.d.). Neighborhood deprivation was calculated for each census block group using the Townsend Deprivation Index (Townsend, Phillimore \& Beattie, 1988) and served as the neighborhood-level independent variable. Unemployment, car ownership, home ownership, and overcrowding were the four indicators used in the index. The neighborhood data were obtained from the 2000 U.S. census data. A higher deprivation index score suggested a greater neighborhood disadvantage (Townsend, Phillimore \& Beattie, 1988).

\section{Statistical analysis}

All statistical analysis were conducted using using SAS version 9.2 (SAS Institute Inc, Cary, NC) with descriptive statistics and mixed model procedures. Descriptive statistics including mean, standard deviation, or frequencies were obtained for each individual and neighborhood independent variable and the dependent variable. When constructing the multi-level linear mixed models, two continuous variables, age and BMI, were transformed into the natural log values in order to meet the assumption of normality for multi-level linear mixed modeling. After examining the sample covariance matrices among individual variables, the compound symmetry error covariance structure was chosen for the purpose of achieving a fit of the current data set in the full model. Both fixed and random 
effects for each individual and neighborhood independent variables were estimated and tested at a statistically significant level of $\mathrm{p}<0.05$. Three 2-level linear models were built: a one-way Analysis of Variance (ANOVA) model, a regression with means-as-outcome, and an intercepts- and slopes-as-outcomes model [33].

\section{Model 1.}

The one-way ANOVA model was an unconditional model in order to examine the variation in the non-fasting blood glucose levels within and between neighborhoods (Mozaffarian, Kamineni, Carnethon, et al., 2009). Y (nonfasting blood glucose level) ij represented each individual participant's blood glucose level within a neighborhood. $\beta_{0 \mathrm{j}}$ represented the mean blood glucose level of a neighborhood. rij indicated the unexplained level-1 variation $(\sigma 2)$ in the blood glucose levels within a neighborhood. $\Upsilon_{00}$ represented the grand mean of the blood glucose levels across all neighborhoods or the average of the neighborhood means on blood glucose levels across the participants of all neighborhoods. u0j indicated the unexplained level-2 variation $(\tau 00)$ in the mean blood glucose levels between neighborhoods (Raudenbush \& Bryk, 2002).

\section{Model 2.}

The regression with means-as-outcome model only had the level-2 variable, neighborhood composite deprivation index, which resulted in an additional estimation of $\Upsilon_{01}$. This model explored the relationship between the neighborhood level deprivation and the mean non-fasting blood glucose level of a neighborhood $\left(\beta_{0 \mathrm{j}}\right)$ (Mozaffarian, Kamineni, Carnethon, et al., 2009). $\Upsilon_{01}$ represented the effect of neighborhood level deprivation on the mean blood glucose level of a neighborhood $\left(\beta_{0 \mathrm{j}}\right)$. u0j indicated the level-2 random variance in the average blood glucose levels between neighborhoods after controlling for the effect of neighborhood deprivation (Raudenbush \& Bryk, 2002).

Model 3. The intercepts- and slopes-as-outcomes model included all individual and neighborhood level independent variables. This model explored the conditional accountability of variability within and between neighborhoods (Raudenbush \& Bryk, 2002). Both age and BMI were grand-mean centered after being transformed to their $\log$ values. $\beta_{1 \mathrm{j} . . . . .} \beta_{7 \mathrm{j}}$ predicted the degree of strength between an individual independent variable and the dependent variable within a neighborhood. $\Upsilon_{10 \ldots \ldots} \Upsilon_{70}$ explained on average, the main effect of gender, race, education, self-reported smoking, self-reported physical activity, age, and BMI on an individual's blood glucose level across all neighborhoods. $\Upsilon_{11 \ldots . . .} \Upsilon_{71}$ explained the interaction between the level-2 variable and each level-1 independent variable or the effect of the level-2 variable on the level-1 slopes $\left(\beta_{1 j \ldots . .} \beta_{7 j} u_{1 j} \ldots . . . u_{7 j}\right.$ suggested the neighborhood variance in each slope after controlling for neighborhood deprivation and level-1 individual variables (Raudenbush \& Bryk, 2002).

\section{Results}

The mean blood glucose level of the participants was $103.61 \mathrm{mg} / \mathrm{dL}$ as detailed in Table 1 . The majority of participants were female (65.5\%) and either White (43.9\%) or African-American (45.8\%). More than half of the participants $(60.4 \%)$ completed at least some college. The average age of this sample was 47 years old with a range from 18 to 96 . The mean BMI of the final sample was 29.01 . 


\begin{tabular}{|c|c|c|c|}
\hline $\begin{array}{l}\text { Measures } \\
\text { Individual level }\end{array}$ & Percentage & Mean (SD) & \\
\hline Gender & & & \\
\hline Male & $34.4 \%$ & & Table 1: Descriptive \\
\hline Female & $65.5 \%$ & & Statistics for Individual \\
\hline Race & & & and Neighborhood \\
\hline $\begin{array}{l}\text { White } \\
\text { African-American }\end{array}$ & $\begin{array}{l}43.9 \% \\
45.8 \%\end{array}$ & & Measures with \\
\hline Other & $8.5 \%$ & & Participants in the CITIES \\
\hline Education & & & program, Guilford and \\
\hline $\begin{array}{l}\text { Less than high school } \\
\text { High school graduate/GED }\end{array}$ & $\begin{array}{l}7.2 \% \\
30.5 \%\end{array}$ & & Forsyth Counties, NC, \\
\hline More than high school & $60.4 \%$ & & $2004-2008$ \\
\hline Self-reported Smoking & & & \\
\hline No & $81.3 \%$ & & \\
\hline Yes & $18.7 \%$ & & \\
\hline Self-reported Physical Activity & & & \\
\hline No & $50.1 \%$ & & \\
\hline Yes & $49.9 \%$ & & \\
\hline Age, years & & 47.23(14.47) & \\
\hline BMI & & $29.01(6.54)$ & \\
\hline Neighborhood Level & & & \\
\hline $\begin{array}{l}\text { Composite Deprivation Index } \\
\text { Health Outcome }\end{array}$ & & $.36(3.28)$ & \\
\hline Non-fasting Blood Glucose Level (mg/dL) & & $103.61(36.70)$ & \\
\hline Total Cases $(\mathrm{N})$ & 12,809 & & \\
\hline
\end{tabular}

One-way ANOVA, regression with means-as-outcomes, and intercepts- and slopes-as-outcomes, are illustrated in Table 2. In model 1, the estimated neighborhood mean blood glucose levels was $103.59 \mathrm{mg} / \mathrm{dL}$. The mean blood glucose level of each neighborhood significantly varied from one neighborhood to another (estimated $\tau 00$ $=13.39 ; \mathrm{p}<.001)$. After including the neighborhood deprivation index in model 2 , the neighborhood composite deprivation index was a significant predictor of each neighborhood's mean blood glucose level $\left(\Upsilon_{01}=.69 ; \mathrm{p}<.001\right)$. After controlling for the effect of the composite deprivation index, at level-2, the unexplained variation in the neighborhood mean blood glucose level remained significant $(\tau 00=7.22 ; \mathrm{p}=.02)$. From model 1 to model 2 , neighborhood level deprivation explains about $46 \%$ of the variance in mean blood glucose levels between neighborhoods.

In Table 2, model 3 estimated the average neighborhood mean blood glucose levels to be $109.80 \mathrm{mg} / \mathrm{dL}$. The neighborhood composite deprivation index remained a statistically significant predictor of each neighborhood's mean blood glucose level $\left(\Upsilon_{01}=.36 ; \mathrm{p}=.004\right)$ after controlling for individual level risk factors. A greater deprivation index score predicted a higher neighborhood mean on blood glucose level. Thus the unexplained variance in mean blood glucose levels in model 2 was no longer significant once the deprivation index and the individual level risk factors were controlled for $(\tau 00=.18 ; \mathrm{p}=.09)$. 


\begin{tabular}{|c|c|c|c|c|}
\hline Measures & $\begin{array}{l}\text { Model } 1 \\
\text { Fixed Effects }\end{array}$ & $\begin{array}{l}\text { Model } 2 \\
\text { Fixed Effects }\end{array}$ & \multicolumn{2}{|l|}{$\begin{array}{l}\text { Model } 3 \\
\text { Fixed Effects }\end{array}$} \\
\hline Individual Level & Estimates SE $p$ value & Estimates SE $p$ value & Estimates SE & $p$ value \\
\hline Gender $\left(\Upsilon_{10}\right)$ & & & $\begin{array}{ll}-5.86 \quad .69\end{array}$ & $<.001$ \\
\hline \multicolumn{5}{|l|}{ Race $\left(\Upsilon_{20}\right)$} \\
\hline White & & & -5.26 & $<.001$ \\
\hline African-American & & & $-3.25 \quad 1.30$ & .01 \\
\hline Other & & & \multicolumn{2}{|l|}{ Reference } \\
\hline \multicolumn{5}{|l|}{ Education $\left(\Upsilon_{30}\right)$} \\
\hline Less than high school & & & 2.98 & .03 \\
\hline High school graduate/GED & & & 3.02 & $<.001$ \\
\hline More than high school & & & \multicolumn{2}{|c|}{ Reference } \\
\hline Self-reported Smoking $\left(\Upsilon_{40}\right)$ & & & 2.83 & .001 \\
\hline Self-reported Physical Activity $\left(\Upsilon_{50}\right)$ & & & -1.00 & .13 \\
\hline Age $\left(\Upsilon_{60}\right)$ & & & 16.12 & $<.001$ \\
\hline $\mathrm{BMI}\left(\Upsilon_{70}\right)$ & & & 21.53 & $<.001$ \\
\hline \multicolumn{5}{|l|}{ Neighborhood Level } \\
\hline $\begin{array}{l}\text { Composite Deprivation Index }\left(\Upsilon_{01}\right) \\
\text { Health Outcome }\end{array}$ & & $<.001$ & .36 & .004 \\
\hline Non-fasting Blood Glucose Level $\left.\Upsilon_{00}\right)$ & $103.59 .38<.001$ & $103.39 .36<.001$ & 109.801 .36 & $<.001$ \\
\hline Health Outcome & Random Effects & Random Effects & Random Effe & \\
\hline Non-fasting Blood Glucose Level $\left(\tau_{00}\right)$ & $13.39 \quad 3.94<.001$ & $\begin{array}{ll}7.22 & 3.57 \\
\end{array}$ & $.18 \quad 1.72$ & .09 \\
\hline
\end{tabular}

Table 2: Results from One-Way ANOVA, Regression with Means-as-Outcomes, and Intercepts- and Slopes-as-Outcomes Models with Participants in the CITIES program, Guilford and Forsyth Counties, NC, 2004-2008

With the exception of self-reported physical activity, on average, across all the neighborhoods, each of the remaining level-1 variables were significantly associated with the individual blood glucose levels. Females were more likely to have a lower glucose level than the males $\left(\Upsilon_{10}=-5.86 ; p<.001\right)$. Participants who smoked more tended to have a higher glucose level $\left(\Upsilon_{40}=2.83 ; p=<.001\right)$. Increases in age or BMI were significant predictors of increased blood glucose levels $\left(\Upsilon_{60}=16.12 ; p<.001, \Upsilon_{70}=21.53 ; p<.001\right)$. Compared to the White participants, African Americans were more likely to have higher glucose levels, while less likely than the participants from other ethnic groups (e.g. Pacific Islander, Asian, American-Indian, and Latino/Hispanic) $\left(\Upsilon_{20 \text { white }}=-5.26 ; p<.001, \Upsilon_{20 \text { African-American }}\right.$ $=-3.25 ; p=<.01)$. A predictive relationship between more education and lower glucose levels was also found among the participants $\left(\Upsilon_{30 \text { less than high school }}=2.98 ; p=.03, \Upsilon_{30 \text { high school graduate/GED }}=3.02 ; p<.001\right)$. The difference of the least squares means of the glucose levels between the White and African American participants was statistically significant ( $p=.010)$ while significance was not found between the groups of less than high school and high school graduate or GED, Table 3.

\begin{tabular}{llrrr} 
Measures & Mean Differences & SE & t value & $p$ value \\
\hline Race & & & & \\
$\quad$ White/African-American & -2.01 & .77 & -2.59 & .010 \\
White/Other & -5.26 & 1.29 & -4.09 & $<.001$ \\
$\quad$ African-American/Other & -3.25 & 1.30 & -2.50 & .01 \\
Education & & & & \\
$\quad$ Less than high school/High school graduate or GED & -.04 & 1.40 & -.03 & .98 \\
$\quad$ Less than high school/More than high school & 2.98 & 1.37 & 2.18 & .03 \\
High school graduate or GED/More than high school & 3.02 & .74 & 4.11 & $<.001$ \\
\hline Abbreviation: SE, standard error; CITIES, Community Initiative to Increase Risk Awareness and \\
Eliminate Stroke
\end{tabular}

Table 3:

Differences of Least Squares Means of

Race and Education with Participants in the CITIES,

Guilford and Forsyth Counties, NC, 2004-2008 


\section{Discussion}

Findings from this study indicate that where an individual lives matters for health outcomes, consistent with findings from previous studies. Living in high-deprived neighborhoods increases the likelihood of having high blood glucose levels and the risk for developing type 2 diabetes. Similarly when compared to people who resided in more affluent neighborhoods, people in the poorest neighborhoods were more likely to experience diabetes (Menec, Shooshtari, Novicki, et al., 2010; Gaskin, Thorpse, McGinty, Bower, Rohde, Young, La Veist, \& Dubay, 2013). These findings are consistent with findings from the Moving to Opportunity project (Ludwig, Sanbonmatsu, Gennetian, Adam, Duncan, Katz, Kessler, Kling, Lindau, Whitaker, \& Wade, 2011). Results of that randomized study indicated that when individuals moved from high-deprived neighborhoods to less deprived neighborhoods, their prevalence of obesity and diabetes declined significantly. Possible explanations for the reductions include changes in eating and physical activity habits due to an increase in access and availability of fresh fruits and vegetables and recreational areas (Ludwig, Sanbonmatsu, Gennetian, Adam, Duncan, Katz, Kessler, Kling, Lindau, Whitaker, \& Wade, 2011).

In addition to neighborhood level deprivation, race was a significant predictor of glucose levels. Although race was examined separately from neighborhood level deprivation they are related. An explanation for how place is related to the greater incidence and prevalence of diabetes among African Americans is that poor African Americans tend to live in neighborhoods with more concentrated poverty, whereas poor Whites tend to live in less deprived neighborhoods (Gaskin, Thorpe, McGinty, Bower, Rohde, Young, LaVeist, \& Dubay, 2013). LaVeist and colleagues found that the social environment explained a significant portion of the variance in diabetes between African Americans and Whites (LaVeist, Pollack, Thorpe, Fresahazion, \& Gaskin, 2011). In this study, results indicated that when African Americans and Whites live in the same neighborhoods, differences in type 2 diabetes are minimized due to increased type 2 diabetes among White residents (LaVeist, Pollack, Thorpe, Fresahazion, \& Gaskin, 2011).

This study has several strengths including using multilevel modeling to examine the unique contribution that neighborhood level deprivation had on residents' blood glucose levels and having a relatively large sample population increased the statistical power. Using a composite index as a measure of neighborhood deprivation may be a better estimate of true neighborhood level poverty than a single measure. Another strength of this study was the large number of African American participants. Previous statistics have suggested that the risk for African-Americans having diabetes were 1.8 times higher than non-Hispanic Whites (American Diabetes association, 2011). Literature on diabetes, race and place indicate that African American neighborhoods tend to characterize by higher poverty, which may be one reason that African Americans are at greater risk for developing diabetes (Gaskin, Thorpe, McGinty, Bower, Rohde, Young, LaVeist, \& Dubay, 2013).

Limitations to the study include, the self-reported of some of the individual level data, such as smoking status, amount of physical activity, and fasting status. This may introduce inaccurate information into the study because of the participants' reluctance to report, misclassifying themselves into a wrong exposure group, and having limited recall (Gordis, 2004). Moreover, the significance of the relationship between the participants' physical activity levels and their blood glucose levels was not detected in this study. This discrepancy with previous results could simply be caused by the classification of the responses to the particular question. The responses were only categorized into physical activity or lack of physical activity, and may not capture the actual pattern of the participants' physical activity. Data extracted for this study was from the CITIES, a stroke risk factor screening program, which was not particularly designed to examine the issues related to diabetes. Therefore, the information that can be fully applied to this study was limited. Also, due to the cross-sectional nature of this study, evidence for a causal relationship between individual and neighborhood level risk factors and non-fasting glucose levels is not provided and generalizability of the results is limited (Gordis, 2004). Furthermore, for this study census block groups were used as a proxy for 
neighborhoods. These large geographic areas may not accurately characterize features of the neighborhoods that impact individuals' health. Future studies are needed that use a smaller geographic area that may better capture the characteristics of neighborhoods (Diez-Roux, 2003).

\section{Conclusion}

Neighborhoods with high deprivation are characterized by a lack of community level resources [35,36]. Additionally they often lack the political power to change things on their own. In conclusion, with findings from this studying indicating that $46 \%$ of the variance in blood glucose levels between neighborhoods is related to neighborhood level deprivation, place matters related to health outcomes. Due to this, interventions to change behavior or increase access to health services will remain limited in their ability to reduce the incidence of chronic diseases. Although the mechanism underlying the association between neighborhood level deprivation and increased blood glucose levels are not yet understood, these findings provide a foundation for prevention efforts and for future studies to examine why these relationships exist. One approach for diabetes prevention is to change the socioeconomic environment of neighborhoods. Policymakers could use this information to address the problems associated with neighborhood level poverty (inadequate housing, lack of availability and access to recreational areas and fresh fruits and vegetables, and crime). Developing policies to change environmental conditions and reduce concentrated poverty can address chronic health issues as well as reduce health disparities

\section{Acknowledgements}

This study was approved by the Institutional Review Boards of Novant Health Systems and the University of North Carolina at Greensboro. The original study was funded by an Office of Minority Health, Department of Health and Human Services Award \# 93.004. Secondary data were used for this study. The authors thank Dr. Chere Chase, Ms. LaPronda Spann, and Ms. Lealia Martin for their contributions to the program implementation. They also thank Dr. Scott Richter for his support to the statistical data analysis

\section{References}

American Diabetes Association. African Americans \& Complications. Alexandria, VA: American Diabetes Association; $2011 \quad$ (http://www.diabetes.org/living-with-diabetes/complications/african-americans-andcomplications.html ). (Accessed April 18, 2011).

Auchincloss, A. H., Diez- Roux, A. V., Mujahid, M. S., et al. (2009). Neighborhood resources for physical activity and healthy foods and incidence of type 2 diabetes mellitus. Archives of Internal Medicine,169,1698-1704.

Bassuk, S. S. \& Manson, J. E. (2005). Epidemiological evidence for the role of physical activity in reducing risk of type 2 diabetes and cardiovascular disease. Journal of Applied Physiology 99,1193-1204.

Carey, V. J., Walters, E. E., Colditz, G. A., et al. (1997). Body fat distribution and risk of non-insulin-dependent diabetes mellitus in women: the Nurses’ Health Study. American Journal of Epidemiology, 145, 614-619.

Centers for Disease Control and Prevention. 2011 National Diabetes Fact Sheet. Atlanta, GA: Center for Disease Control and Prevention; 2011. (http://www.cdc.gov/diabetes/pubs/pdf/ndfs_2011.pdf). (Accessed March 13, 2014)

Cox, M., Boyle, P. J., Davey, P. G., et al. (2007). Locality deprivation and Type 2 diabetes incidence: a local test of relative inequalities. Social Science Medicine, 65, 1953-1964. 
Diex-Roux, A. V. (2003). Residential environment and cardiovascular disease risk. Journal of Urban Health, 80(4), 569-589.

Ford, E. S., Williamson, D. F., \& Liu, S. (1997). Weight change and diabetes incidence: findings from a national cohort of US adults. American Journal of Epidemiology146, 214-222.

Gordis, L. (2004). Epidemiology. 3nd ed. Philadelpia, PA: Elsevier Saunders.

Gaskin, D. J., Thorpe, R. J., McGinty, E. E., Bower, K., Rohde, C., Young, J. H., LaVeist, T. A., \& Dubay, L. (2013). Disparities in Diabetes: The nexus of race, poverty, and place. American Journal of Public Health, e1-e9.

Gordon-Larsen, P., Nelson, M. C., Page, P., et al. (2006). Inequality in the built environment underlies key health disparities in physical activity and obesity. Pediatrics, 117, 417-424.

Harris, M. I. (1991). Epidemiological correlates of NIDDM in Hispanics, Whites, and Blacks in the U.S. population. Diabetes Care, 14, 639-648.

Harris, M. I., Klein, R., Cowie, C. C., et al. (1998). Is the risk of diabetic retinopathy greater in non-Hispanic blacks and Mexican Americans than in non-Hispanic whites with type 2 diabetes? A U.S. population study. Diabetes Care, 21, 1230-1235.

Hoyert, D. L. \& Xu, J. (2012). Deaths: Preliminary Data for 2011. National Vital Statistics Reports, 61(6). Hyattsville, MD: National Center for Health Statistics. Available from http://www.cdc.gov/nchs/fastats/deaths.htm. (Accessed March 24, 2014)

Huang, E. S., Basu, A., O’Grady, M., \& Capretta, J. C. (2009). Projecting the future diabetes population size and related costs for the U.S. Diabetes Care, 32(12), 2225-2229.

Inagami, S., Cohen, D. A., Brown, A. F., et al. (2009). Body mass index, neighborhood fast food and restaurant concentration, and car ownership. Journal of Urban Health, 86, 683-695.

Joshy, G., Porter, T., Levre, C. L., et al. (2009). Prevalence of diabetes in New Zealand general practice: the influence of ethnicity and social deprivation. Journal of Epidemiology and Community Health, 63, 386-390.

Koh-Banerjee, P., Wang, Y., Hu, F. B., et al. (2004). Changes in body weight and body fat distribution as risk factors for clinical diabetes in US men. American Journal of Epidemiology, 159,1150-1159.

Krishnan, S., Cozier, Y. C., Rosenberg, L., et al. (2010). Socioeconomic status and incidence of type 2 diabetes: results from the Black Women's Health Study. American Journal of Epidemiology, 171,564-570.

LaVeist, T., Pollack, K., Thorpe, R., Fresahazion, R., \& Gaskin, D. (2011). Place, not race: Disparities dissipate in Southwest Baltimore when Blacks and Whites live under similar conditions. Health Affairs, 30(10), 1880-1887.

Lovasi, G. S., Hutson, M. A., Guerra, M., et al. (2009). Built environments and obesity in disadvantaged populations. Epidemiological Review, 31, 7-20.

Ludwig, J., Sanbonmatsu, L., Gennetian, L., Adam, E., Duncan, G. J., Katz, L. F., Kessler, R. C., Kling, J. R., Lindau, S. T., Whitaker, R. C., \& Wade, T. W. (2011). Neighborhoods, obesity, and diabetes - A randomized social experiment. The New England Journal of Medicine, 365(16), 1509-1519.

Mayo Clinic. Diabetes. Rochester, MN: Mayo Clinic; 2010.

(http://www.mayoclinic.com/health/diabetes/DS01121/DSECTION=tests-and-diagnosis). (Accessed October 22, 2010). 
Menec, V. H., Shooshtari, S., Novicki, S., et al. (2010). Does the relationship between neighborhood socioeconomic status and health outcomes persist into very old age? A population-based study. Journal of Aging and Health, 22, 2747.

Miller, E. M., Schulz, M. R., Bibeau, D., L., Galka, A. M., Spann, L. I., Martin, L. B., Aronson, R. E., \& Chase, C. M. (2007). Factors associated with misperception of weight in the stroke belt. Journal of General and Internal Medicine, 23(3), 323-328.

Mokdad, A. H., Ford, E. S., Bowman, B. A., et al. (2003). Prevalence of obesity, diabetes, and obesity-related health risk factors, 2001. Journal of the American Medical Association, 289, 76-79.

Mozaffarian, D., Kamineni, A., Carnethon, M., et al. (2009). Lifestyle risk factors and new-onset diabetes mellitus in older adults: the Cardiovascular Health Study. Archives of Internal Medicine, 169, 798-807.

National Institutes of Health. Diagnosis of Diabetes. Bethesda, MD: National Institutes of Health; 2008. (http://diabetes.niddk.nih.gov/dm/pubs/diagnosis/\#what) (Accessed October 22, 2010)

Pan, X. R., Yang, W. Y., Li, G. W., et al. (1997). Prevalence of diabetes and its risk factors in China, 1994. Diabetes Care, 20,1664-1669.

Raudenbush, S. \& Bryk, A. (2002). Hierarchical Linear Models: Applications and Data Analysis Methods. 2nd ed. Newbury Park, CA: Sage.

Robbins, J. M., Vaccarino, V., Zhang, H., et al. (2001). Socioeconomic status and type 2 diabetes in African American and Non-Hispanic White women and men: evidence from the third National Health and Nutrition Examination Survey. American Journal of Public Health, 91,76-83.

Sallis, J. F., Saelens, B. E., Frank, L. D., et al. (2009). Neighborhood built environment and income: examining multiple health outcomes. Social Science Medicine, 68, 1285-1293.

Schiller, J. S., Lucas, J. W., Ward, B. W., \& Peregoy, J. A. (2012). Summary health statistics for U.S. adults: National Health Interview Survey, 2010. National Center for Health Statistics. Vital Health Statistics 10(252).

Schootman, M., Andresen, E, M,, Wolinsky, F. D., et al. (2007). The effect of adverse housing and neighborhood conditions on the development of diabetes mellitus among middle-aged African Americans. American Journal of Epidemiology166, 379-389.

Taylor, W. C., Carlos-Poston, W. S., Jones, L., et al. (2006). Environmental justice: obesity, physical activity, and healthy eating. Journal of Physical Activity and Health, 3(suppl), 30S-45S.

Townsend, P., Phillimore, P., \& Beattie, A. (1988). Health and Deprivation: Inequality and the North. New York, NY: Croom Helm.

U.S. Census Bureau. U.S. Department of Commerce. Cartographic Boundary Files. Washington, DC: U.S. Census Bureau. (http://www.census.gov/geo/www/cob/bg_metadata.html). (Accessed April 22, 2009).

U.S. Department of Human and Health Services. Community Initiatives to Eliminate Stroke Program FY 2004-2007. Washington, DC: U.S. Department of Human and Health Services; 2005. (http://www.omhrc.gov/templates/content.aspx?ID=3342). (Accessed September 21, 2007).

Willi, C., Bodenmann, P., Ghali, W. A., et al. (2007). Active smoking and risk of type 2 diabetes. Journal of the American Medical Association, 298, 2654-2664. 